\title{
Avaliação da relação entre o grau de retenção dentária e o tipo de retalho mais indicado para a cirurgia de remoção de terceiros molares inferiores retidos
}

\author{
Evaluation of the relation between the degree of dental impact and the \\ most indicated flap for the surgery of impacted lowers third molars.
}

NUNES, Leandro Soeiro de Souza* HEITZ, Cláiton**

LORO, Raphael Carlos Drumond***

SILVA, Roberto Fernandes Carvalho $\mathrm{e}^{* * * *}$

\begin{abstract}
RESUMO
O tratamento cirúrgico de dentes retidos, especialmente os terceiros molares, é uma das atividades cirúrgicas realizadas com maior freqüência nos consultórios odontológicos. A localização das incisões e a escolha do tipo de retalho são determinadas em função do acesso desejado e das estruturas anatômicas relacionadas.

$\mathrm{O}$ objetivo do presente trabalho foi comparar quanto à cicatrização, deiscência de sutura e indicações, as incisões angulares com relaxante na mesial do segundo molar ou na distal do segundo molar, a incisão em envelope e a incisão em V.

Foram atendidos 34 pacientes que possuíam terceiros molares inferiores retidos. Os pacientes foram divididos nos quatro grupos de diferentes retalhos. Ao final do estudo, observou-se que o grau de retenção influencia no tipo de retalho escolhido.
\end{abstract}

\section{PALAVRAS-CHAVE \\ Cirurgia. Terceiro molar retido. Retalho}

\section{INTRODUÇÃO}

Denominam-se dentes retidos aqueles que, uma vez chegada a época normal de seu irrompimento, ficam encerrados parcial ou totalmente no interior do tecido ósseo (Centeno, 1978). O tratamento cirúrgico de dentes retidos, especialmente os terceiros molares, é uma das atividades cirúrgicas realizadas com maior freqüência nos consultórios odontológicos. Segundo Scherstein et al (1988), os terceiros molares estão presentes em $90 \%$ da população, sendo que em $33 \%$ eles se encontram retidos. De acordo com Graziani (1995), o principal fator etiológico das inclusões dentárias parece ser a falta de espaço no arco dental, visto que os últimos dentes a realizarem a erupção (terceiros molares e caninos superiores) são, normalmente, os dentes mais acometidos. Além disso, outras causas locais podem ser citadas, tais como a perda prematura ou a permanência exagerada dos dentes temporários, obstáculo oferecido pelo dente vizinho, resistência demasiada do tecido ósseo e obstáculo causado pela densidade ou inflamação fibromucosa. Archer (1975), refere-se à redução gradual do tamanho dos maxilares como um dos fatores responsáveis pelas retenções desses dentes.

A remoção de dentes retidos tem como objetivo a prevenção da saúde bucal, pois pretende evitar que outras patologias se ins- talem, como doença periodontal, cárie, pericoronarite, cistos e tumores odontogênicos, reabsorções radiculares, fratura de mandíbula, osteomielites, trismos, dor de etiologia desconhecida e maloclusão (Medeiros et al, 2003).

A localização das incisões e a escolha do tipo de retalho para a cirurgia de dentes retidos são determinadas em função do acesso desejado e das estruturas anatômicas relacionadas. $\mathrm{O}$ retalho mucoperiostal deve permitir boa visualização do campo operatório e a linha de incisão deve repousar sobre osso hígido, prevenindo, assim, o colapso do retalho e a deiscência da sutura.

Em relação aos tipos de retalhos mais utilizados nas cirurgias de terceiros molares retidos, podemos citar o retalho em envelope e o retalho com uma incisão relaxante, retalho angular ou em L (Medeiros et al, 2003; Zanini, 1990; Guralnick, 1984; Olivieri e Berhau, 2002).

O objetivo do presente trabalho é comparar, quanto à cicatrização, deiscência de sutura e indicações, as incisões angulares com relaxantes na mesial do segundo molar ou na distal do segundo molar, a incisão em envelope e a incisão em V.

\section{REVISÃO DE LITERATURA}

Conforme Graziani (1986) a incisão para a remoção de um terceiro molar retido deve ser praticada sobre apoio ósseo, nunca saindo do rebordo alveolar, ou para longe da borda anterior do ramo da mandíbula. A localização das incisões e a escolha do tipo de retalho para a cirurgia dos dentes retidos são determinadas em função do acesso desejado e das estruturas anatômicas relacionadas, devendo ser amplo e planejado com margem de segurança (Medeiros et al, 2003).

Com o objetivo de proteger o retalho de traumatismos durante o trans-operatório, Centeno (1978) aconselha a realização de uma pequena incisão perpendicular sobre a papila distal do segundo molar, além da incisão que se estende sobre a face oclusal do terceiro molar retido.

Chin Quee et al (1985) estudaram as influências do tipo de retalho sobre o periodonto do segundo molar adjacente após a remoção de terceiros molares inferiores. Em um grupo de pacientes, eles realizaram incisões em envelope e no outro, foi utilizada a técnica descrita por Thoma (1932), onde a incisão sobre o rebordo do terceiro molar deve terminar $2 \mathrm{~mm}$ antes do segundo molar, e a partir desse ponto é feita uma incisão relaxante vestibular em direção ao fundo de sulco. A conclusão dos autores foi que o tipo de retalho não influencia no grau de perda do ligamento distal.

Stephens et al (1983) avaliaram as con-

\footnotetext{
* Aluno do curso de especialização em CTBMF na ULBRA-RS

** Mestre em CTBMF e Doutor em Estomatologia pela PUC-RS *** Mestre em CTBMF pela PUC-RS, Doutorando em CTBMF PUC-RS ***** Especialista em CTBMF pela PUC-RS
} 
dições periodontais do segundo molar adjacente, utilizando dois diferentes tipos de retalho. Foram comparadas as incisões em envelope, como a proposta por Szymd (1971), e o retalho com uma incisão relaxante na distal do segundo molar, oblíqua, em direção ao fundo de sulco. Após as avaliações pós-operatórias, os autores concluíram que não houve diferenças clínicas significativas entre os dois tipos de retalho.

Schofield et al (1988) compararam os retalhos com e sem incisão relaxante, em relação aos tecidos periodontais do segundo molar adjacente. A conclusão dos autores foi que, após um ano de acompanhamento, as condições periodontais do segundo molar não apresentavam diferenças com a utilização das diferentes técnicas.

Peterson (1998) coloca que o retalho deve ter uma amplitude tal que permita a colocação e a estabilização de afastadores e de instrumentos para a remoção de osso. A melhor cicatrização e maior facilidade de ser fechado, fazem com que o retalho em envelope seja a técnica preferencial deste autor. Entretanto, se o cirurgião necessita de um acesso maior a regiões mais apicais do dente, pode tencionar a dilacerar o retalho em envelope. Nessas situações deve-se considerar o uso de um retalho triangular.

Paza (1999) comparou os resultados de duas técnicas de incisões para a extração de terceiros molares retidos. Na técnica $\mathrm{A}$, foi realizada uma incisão vertical de alívio de tensão na mesial do segundo molar. Na técnica $\mathrm{B}$, a incisão relaxante foi localizada na distal do segundo molar. Segundo o autor, na técnica A foi verificada maior segurança no procedimento cirúrgico em relação à retirada óssea, na preservação da integridade do retalho e dos tecidos moles adjacentes, maior estabilidade imediata e mediata, além de menor possibilidade de deiscência de sutura e retração do retalho.

A incisão de escolha de Escoda e Aytés (1999) é a angular, que se inicia na borda anterior do ramo ascendente, cruzando o triângulo retromolar até a face distal do segundo molar. No ângulo distovestibular do $2^{0}$ molar é realizada uma incisão relaxante vestibular, ou, então, se continua a incisão no sulco vestibular do segundo molar e a incisão relaxante é realizada na mesial desse dente. A eleição de uma ou outra técnica dependerá do grau de dificuldade apresentado pelo dente retido. De acordo com os autores, o retalho em envelope é mais fácil de suturar, menos dolorido no pós-operatório e a cicatrização é mais rápida e com menos complicações. No entanto, ele oferece um campo operatório mais limitado, por isso está indicado para dentes retidos em posição alta, favorável e quando se prevê que não será necessário realizar odontosec- ção.

Jakse et al (2002) avaliaram a influência do desenho do retalho na cicatrização primária, em 60 cirurgias de terceiros molares inferiores retidos. Os autores compararam a técnica do envelope com um retalho triangular modificado. Nessa técnica, é feita uma incisão na zona retromolar, ligeiramente para vestibular, em direção ao segundo molar. A incisão angular é feita na papila distovestibular do segundo molar, em direção ao fundo de sulco, com aproximadamente $10 \mathrm{~mm}$ de comprimento. As avaliações pós-operatórias foram realizadas após 1,7 e 14 dias após a cirurgia e a sutura foi removida após a primeira semana. Eles concluíram que o desenho do retalho influencia consideravelmente a cicatrização primária após a remoção de terceiros molares inferiores, sendo que o triângulo modificado tornou mais fácil a cicatrização por primeira intenção.

Heitz, em artigo no prelo, descreveu uma incisão em $\mathrm{V}$, para a remoção de terceiros molares inferiores retidos. A incisão inicial é feita na papila lingual distal do segundo molar inferior e segue perpendicularmente até o fundo de sulco gengivo-geniano. A segunda incisão tem aproximadamente dois centímetros de comprimento e começa no vértice da primeira, seguindo pela linha oblíqua externa, formando um V. Após o descolamento do retalho mucoperiósteo, desloca-se o vértice da incisão para cima e para lingual, fixando-o com um ponto de reparo no pilar amigdaliano. A osteotomia e odontosecção devem ser realizadas conforme o tipo de retenção dentária, e a sutura é feita através de pontos isolados.

\section{MATERIAIS E MÉTODOS}

Foram atendidos trinta e quatro pacientes (21 mulheres e 13 homens), com idades entre 16 e 39 anos (média $=22,5 \pm 4,5$ ), no período de junho a novembro de 2003 , no ambulatório de Cirurgia da Faculdade de Odontologia de Pontifícia Universidade Católica do Rio Grande do Sul. Trinta e dois pacientes $(94,12 \%)$ eram não fumantes. $O$ pré-requisito para pàrticipar do estudo era que o terceiro molar inferior estivesse retido.

Os dentes retidos foram classificados pelo método de Pell e Gregory (1933) e divididos em quatro grupos. No Grupo 1 , foram realizadas incisões em $\mathrm{L}$ com a incisão relaxante localizada na mesial do segundo molar. No Grupo 2 foram realizadas incisões angulares com a relaxante localizada na distal do segundo molar. No Grupo 3 foi utilizado o retalho em envelope e no Grupo 4 $\mathrm{a}$ incisão em $\mathrm{V}$.

Grupo 1: No retalho com incisão relaxante na mesial do segundo molar, a incisão deve iniciar na área retromolar, próximo à linha oblíqua externa, no aspecto lateral da mandíbula. $\mathrm{O}$ bisturi deve ser direcionado até a metade da face distal do segundo molar adjacente. Após, é feita uma incisão intrasulcular na face vestibular do segundo molar e a incisão relaxante é colocada na mesial desse mesmo dente. Essa incisão não deve ser localizada no centro da papila, e sim ao lado (parapapilar). O deslocamento do retalho é feito de anterior para posterior e da margem gengival para a mucosa alveolar. Após a remoção do dente, a sutura é feita com pontos isolados (Fig. 1).

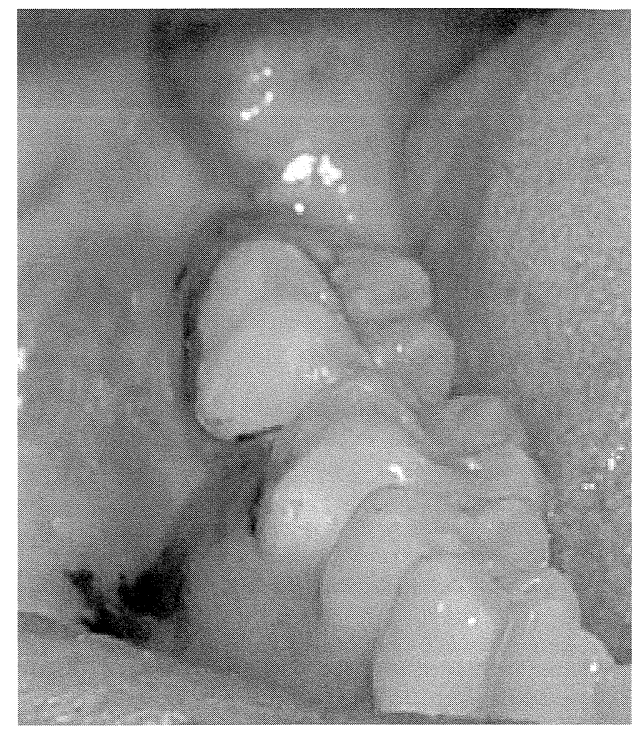

Figura 1 - Retalho com relaxante na mesial do segundo molar

Grupo 2: No retalho com incisão relaxante na distal do segundo molar, a incisão deve iniciar na área retromolar, próximo à linha oblíqua externa, no aspecto lateral da mandíbula. $\mathrm{O}$ bisturi deve ser direcionado até a metade da face distal do segundo molar adjacente. A partir daí, é realizada a incisão relaxante, oblíqua, em direção ao fundo de sulco vestibular. Após a extração do dente incluso, a sutura é feita com pontos isolados (Fig. 2).

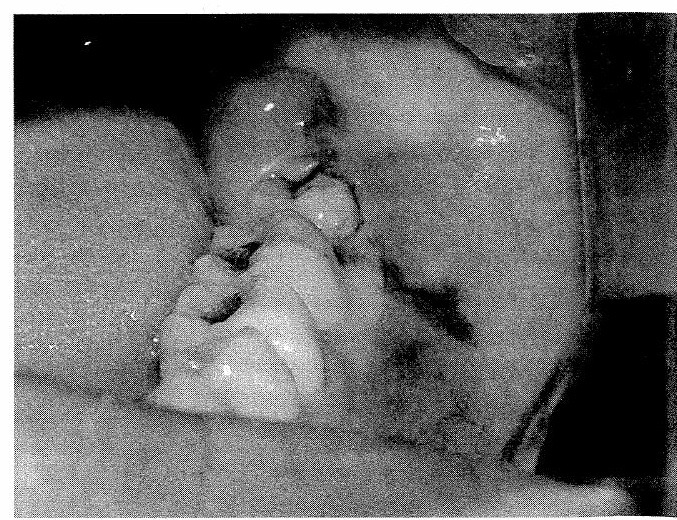

Figura 2-Retalho com relaxante na distal do segundo molar 
Grupo 3: No retalho em envelope, a incisão na área retromolar é feita da mesma maneira descrita para os retalhos angulares e segue intrasulcularmente até a mesial do primeiro molar (Fig.3).

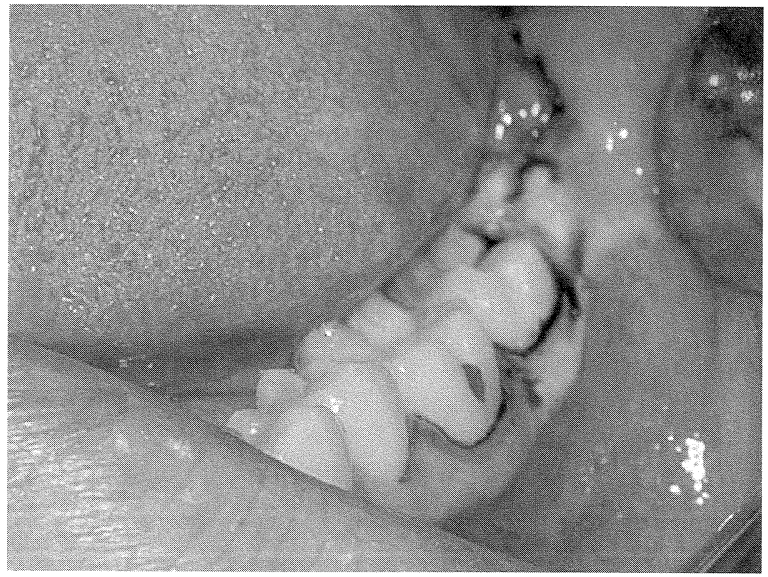

Grupo 4: No retalho em V, a incisão inicial é feita na papila lingual distal do segundo molar inferior e segue perpendicularmente até o fundo de sulco gengivo-geniano. A segunda incisão tem aproximadamente dois centímetros de comprimento e começa no vértice da primeira, seguindo pela linha oblíqua externa, formando um
V. Após o descolamento do retalho mucoperiósteo, desloca-se o vértice da incisão para cima e para lingual, fixando-o com um ponto de reparo no pilar amigdaliano. A osteotomia e odontosecção devem ser realizadas conforme o tipo de retenção dentária, e a sutura é feita através de pontos isolados (Fig. 4).

Figura 3-Retalho em envelope

Classificação de Pell e Gregory: Esta classificação refere-se à posição do terceiro molar em relação ao plano oclusal do segundo molar e à borda anterior do ramo mandibular. Em relação ao plano oclusal, o dente retido pode estar no mesmo nível do plano oclusal do segundo molar (Classe A); pode estar entre o plano oclusal e a linha cervical do segundo molar (Classe AB); pode estar abaixo da linha cervical do segundo molar (Classe C). Em relação à borda anterior do ramo mandibular, o dente retido pode estar totalmente anterior a esta (Classe 1); pode estar metade coberto pela porção anterior do ramo (Classe 2); ou pode estar totalmente coberto pela borda anterior do ramo mandibular (Classe 3)

As avaliações pós-operatórias foram feitas por dois profissionais alheios à pesquisa. Nas avaliações pós-operatórias, realizadas 7 e 14 dias após a cirurgia, foram observadas a cicatrização e a presença, ou não, de deiscência de sutura. As análises dos resultados foram baseadas numa estatística descritiva e no teste $x^{2}$.

Os pacientes foram medicados com Amoxicilina $500 \mathrm{mg}$ ( $\mathrm{VO}$, de $8 / 8 \mathrm{hs}$, por 7 dias) e Paracetamol 750mg (VO, de 6/6hs, por 3 dias) no pós-operatório. A remoção de sutura foi feita após sete dias.

\section{RESULTADOS}

No Grupo 1, o retalho angular com relaxante na mesial do $2^{\circ}$ molar foi realizado em 11 pacientes, dos quais cinco $(45,45 \%)$ apresentavam retenção classe III de Pell e Gregory e os outros 6 casos, classe II (Graf. 1). Com relação à profundidade de retenção, apenas 2 casos $(18,18 \%)$ eram classe
A, e 54,55\% apresentavam retenção classe C (Graf. 2). Para os dentes em posição horizontal este foi o retalho de escolha, sendo uitilizado em $6(54,55 \%)$ cirurgias (Tab. 1).

Em $81,82 \%$ das cirurgias foi realizada odontossecção e em apenas $27,27 \%$ dos pacientes foi observado deiscência de sutura após 7 dias (Tab.2).

Gráfico 1- Relação entre o tipo de retalho utilizado e a profundidade de retenção segundo a Classificação de Pell e Gregory

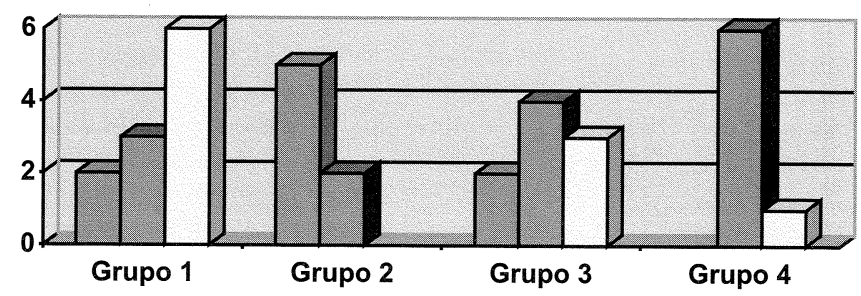

Classe A

Classe B

Classe C

No Grupo 2, formado por 7 pacientes, o retalho angular com incisão relaxante na distal do $2^{\circ}$ molar foi utilizado nas cirurgias que apresentavam retenções submucosas ou intraósseas superficiais do tipo A $(71,43 \%)$ e B $(28,57 \%)$ (Graf. 1) e com inclinação vertical $(100 \%)$ (Tab 1). Em apenas 1 caso foi necessário realizar odontossecção e a deiscência de sutura aos 7 dias pós-operatórios foi de 28,57\% (Tab. 2).

Gráfico 2- Relação entre o tipo de retalho utilizado e a Classificação de Pell e Gregory quanto à posição do dente retido em relação à borda anterior do ramo mandibular

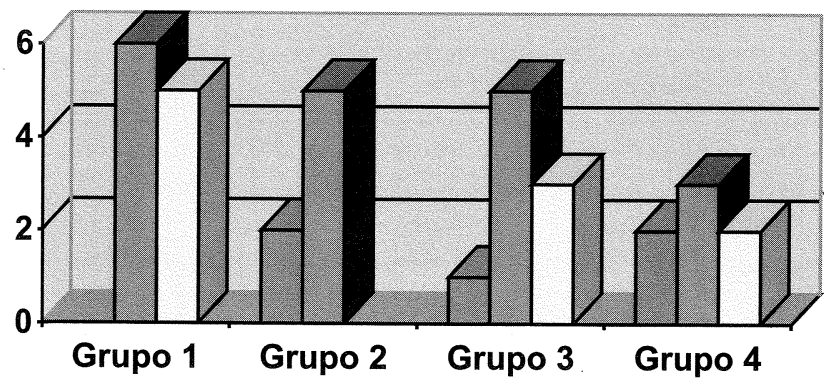


A incisão em envelope (Grupo 3) foi utilizada em 9 pacientes, sendo preterida para os dentes mesioangulados $(66,67 \%)$ (Tab. 1) e para retenções de classe II $(55,56 \%)$, seguido das retenções classe III $(33,33 \%)$ (Graf.2). Quatro casos $(44,44 \%)$ apresentavam retenção tipo $\mathrm{B}$ e 3 casos, tipo C (Graf.1). Somente um paciente $(11,11 \%)$ apresentou deiscência de sutura após 7 dias (Tab.2) e a odontossecção foi realizada em $33,33 \%$ das cirurgias.

Dentre as cirurgias realizadas com o retalho em V (Grupo 4), seis pacientes $(85,71 \%)$ apresentavam retenção tipo B e um, tipo C (Graf.1). Este retalho foi utilizado em 3 casos que apresentavam classificação II, dois classe I, e dois classe III (Graf.2). Dos sete casos operados, 4 apresentavam inclinação vertical (Tab.1). Em 3 cirurgias foram realizadas odontossecção e a incidência de deiscência de sutura no sétimo dia pós-operatório foi de 14,29\%,um caso (Tab.2).

Com o propósito de verificar a provável existência de associação entre o tipo de retalho utilizado e a classificação de Pell e Gregory aplicou-se o teste $x^{2}$ (Chi-square), adotando um nível de significância de $5 \%$ (p = $0,05)$. Em relação ao plano oclusal (profundidade) há uma diferença estatística entre os grupos de incisões $(p=0,12)$. Com relação à borda anterior do ramo mandibular também há uma diferença estatística entre os diferentes grupos $(\mathrm{p}=0,26)$.

\section{DISCUSSÃO}

Este estudo, realizado com 34 pacientes que possuíam terceiros molares inferiores inclusos, mostrou que o nível de retenção dentária influencia na escolha do tipo de retalho utilizado na cirurgia. Estando de acordo, portanto, com as afirmações de Medeiros et al (2003), de que a escolha do tipo de retalho para a cirurgia de dentes inclusos são determinadas em função do acesso desejado; de Jakse et al (2002, que o tipo de retalho influencia na cicatrização primária; e de Escoda e Aytés (1999), que colocam que a escolha de uma ou outra técnica dependerá do grau de dificuldade apresentado pelo dente incluso.

Para as cirurgias dos dentes retidos classe $\mathrm{C}$, foi preterido o retalho angular com relaxante na mesial do segundo molar, por proporcionar um maior campo operatório. Paza (1999) coloca que este tipo de retalho oferece maior segurança em relação à retirada óssea e a preservação da integridade dos tecidos. Peterson (1998) relatou que para a remoção de dentes mais profundos o retalho angular é o mais indicado.

Os resultados deste estudo demonstra-

Tabela 1 - Relação entre o tipo de retalho utilizado e a inclinação do dente retido

\begin{tabular}{|lcccc|}
\hline & Grupo 1 & Grupo 2 & Grupo 3 & Grupo 4 \\
\hline Mesioangulado & 3 & - & 6 & 2 \\
Horizontal & 6 & - & - & 1 \\
Vertical & 1 & 7 & 3 & 4 \\
Distoangulado & 1 & - & - & - \\
\hline
\end{tabular}

\begin{tabular}{|c|c|c|c|c|}
\hline & Grupo 1 & Grupo 2 & Grupo 3 & Grupo 4 \\
\hline Deiscência 7 dias & 3 & 2 & 1 & 1 \\
\hline Deiscência 14 dias & - & 1 & - & - \\
\hline
\end{tabular}

ram que a incidência de deiscência de sutura após sete dias foi semelhante nos grupos 1 , $(27,27 \%)$, e $2,(28,57 \%)$, diferentemente dos achados de Paza (1999), no qual foi relatado maior deiscência de sutura para $o$ retalho com relaxante na distal do segundo molar.

Para as retenções classe $\mathrm{A}$ ou $\mathrm{B}$, todos os retalhos estão indicados e foram utilizados neste estudo. O retalho em envelope foi o que apresentou menor índice de deiscência de sutura aos 7 dias de pós-operatórios $(11,11 \%)$. Os relatos de Escoda e Aytés (1999) e Peterson (1998) concordam com os resultados apresentados neste estudo, em relação a maior facilidade de fechamento deste retalho e uma cicatrização mais rápida e com menos complicações.

A técnica de retalho em $V$, proposta por Heitz et al, em artigo no prelo, mostrou resultados satisfatórios para retenções mais superficiais, oferecendo um bom campo operatório e a proteção do retalho no trans-operatório, devido à sua fixação no pilar anterior amigdaliano durante o ato cirúrgico (Fig.5). A descência de sutura aos 7 dias foi de $14,29 \%$. Assim como no estudo Jakse et al (2002), em que foi proposta a utilização de um retalho triangular modificado e salientado a necessidade de treinamento para a realização do mesmo, esta nova técnica precisa ser utilizada em outros estudos, a fim de verificar a sua aplicabilidade.

\section{CONCLUSÃO}

Assim observa-se que o grau de retenção também influencia no tipo de retalho escolhido; para as retenções mais superficiais todos os retalhos aqui testados podem ser utilizados, entretanto para as retenções mais profundas o retalho angular com relaxante na mesial do segundo molar é o mais indicado; o retalho em envelope parece oferecer um pós-operatório com menores complicações, mas o campo operatório é limitado; o retalho em $\mathrm{V}$ oferece um bom campo opera- tório e uma adequada cicatrização primária, porém necessita ser mais utilizado, a fim de verificarem as suas vantagens e desvantagens em um maior número de cirurgias.

\section{ABSTRACT}

The surgical treatment of impacted teeth, especially the third molars, is one of the most usual surgeries in dental offices. The location of the incisions and the choice of the kind of flap for these kinds of surgeries are determined according to the desired access and related anatomic structures.

The aim of this study was to compare the angled incisions with mesial relieving or distal relieving of the second molar, the envelope incisions and the " $\mathrm{V}$ " incision, in relation to healing, wound dehiscences and indications.

Thirty-four patients who had the lower third molars impacted were assisted. The patients were divided in four groups, according to the different flaps. At the end of the studies, it was observed that the degree of impact influences on the kind of flap chosen.

\section{KEYWORDS}

Surgery. Third molars impacted. Flap

\section{REFERÊNCIAS}

ARCHER, W.H. Dientes retidos. In: ARCHER, W.H. Cirurgía Bucal: atlas paso por paso de técnicas quirúrgicas. v.1. Philadelphia: W.B. Saunders, 1975, Cap.4, p.124-237.

CENTENO, G.A.R. Cirugia bucal. Buenos Aires: El Ateneo, 1978.

CHIN QUEE, T.A. et al. Surgical Removal of the Fully Impacted Mandibular Third Molar. The Influence of Flap Design and Alveolar Bone Height on the Periodontal Status of Second Molar. J Periodontol., v.56, n.10, p.625-30, 1985. 
ESCODA, C.G.; AYTÉS, L.B. Cirurgia bucal. Madrid: Ergon, 1999.

GRAZIANI, M. Cirurgia dos Dentes Inclusos. In: GRAZIANI, M. Cirurgia bucomaxilofacial. 8 ed. Rio de Janeiro: Guanabara Koogan, 1995, Cap.12, p.173-208.

GURALNICK, W. Third Molar Surgery. Br. Dent. J., v.156, p.389-394, 1984.

HEITZ, C.; DIEFENBACH, R.S.; FERREIRA, A.G.M. Incisão em "V" nas Extrações de Terceiros Molares Inferiores Retidos. Rev. Gaúcha Odontol. no prelo, 2003.

JAKSE, N. Primary Wound Healing After Lower Third Molar Surgery: Evaluation of 2 Different Flap Designs. Oral Surg. Oral Méd. Oral Pathol. Oral Radiol. Endod., v.93, p.7-12, 2002.

MARZOLA, C. Retenção Dental. 2 ed. São Paulo: Pancast, 1995.

MEDEIROS, P.J.; MIRANDA, M.S.; RIBEIRO, D.P.B. Cirurgia dos Dentes Inclusos: Extração e Aproveitamento. São Paulo: Santos, 2003.

OLIVIERI, P.; BERRHAU, S. Incisiones Empleadas para Exodoncia de Terceiros Molares Retenidos. Rev. Soc. Odontol. La Plata, v. 29, p.23-27, 2002.

PAZA, A. Estudo Comparativo entre Técnicas de Incisões para Extrações de Terceiros Molares Inferiores Retidos. Tese (Doutorado em Cirurgia) - Pontifícia Universidade Católica, Faculdade de Odontologia, Porto Alegre, 1999.

PELL, G.J.; GREGORY, G.T. Impacted mandibular Third Molars: Classification and Modified Technique for Removal. Dental Dig, v.39, p. 330-338, 1933.

PETERSON, L. Normas de Conduta em Dentes Impactados. In: PETERSON, L.; ELLIS, E. HUPP, J et al. Cirurgia Oral e Maxilofacial Contemporânea. 3. ed. Rio de Janeiro: Guanabara Koogan, 2000, Cap.9, p.214-247.

SCHERSTEIN, E.; LYSEL, L.; ROHLIN, M. Prevalence of Impacted Third Molars in Dental Students. Swed. Dent. I., v.18, p.07-13, 1989.

SCHOFIELD, I.D.F.; KOGON, S.L.; DONNER, A. Long-Term Comparison of
Two Surgical Flap Design for Third Molar Surgery on the Health of the Periodontal Tissue of the Second Molar Tooth. J. Canad. Dent. Assoc., v.54, no.9, p.689-91, 1988.

STEPHENS, R.J.; APP, G.R., FOREMAN, D.W. Periodontal Evaluation of Two Mucoperiostal Flaps Used in Removing Impacted Mandibular Third Molars. J. Oral Maxillofac. Surg., v.41, p.719724, 1983.

SZYMD, L. Mucoperiostal Flap. Dent. Clin. North. Am., v. 15, p.300, 1971.

ZANINI, S.A. Cirurgia e Traumatologia Bucomaxilofacial. Rio de Janeiro: Revinter, 1990.

Recebido: 13 de dezembro/2004 Aceito: 01 de junho/2005

Endereço para correspondência: leandrossnunes@hotmail.com 